\title{
Aqueous Huaier Extract Suppresses Gastric Cancer Metastasis and Epithelial to Mesenchymal Transition by Targeting Twist
}

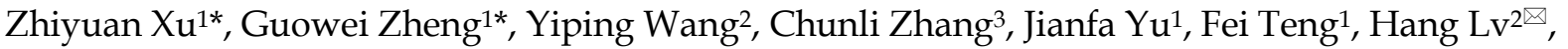 \\ Xiangdong Cheng $1{ }^{\bowtie}$ \\ 1. Department of gastrointestinal surgery, The First Affiliated Hospital of Zhejiang Chinese Medical University, Hangzhou, Zhejiang, China; \\ 2. Key Laboratory of integrated traditional Chinese and Western Medicine for diagnosis and treatment of digestive system tumor, Hangzhou, Zhejiang, China; \\ 3. Department of pathology, The First Affiliated Hospital of Zhejiang Chinese Medical University, Hangzhou, Zhejiang, China. \\ * Zhiyuan Xu and Guowei Zheng contributed equally to this work \\ $\triangle$ Corresponding authors: Name: Xiangdong Cheng, Department of gastrointestinal Surgery, The First Affiliated Hospital of Zhejiang Chinese Medicine University, \\ Youdian Road 54\#, Hangzhou, 310006, Zhejiang, China. Tel: +86-571-87070965; Fax: +86-571-87070965; E-mail: getfar@zcmu.edu.cn Name: Hang Lv, Key Laboratory of \\ integrated traditional Chinese and Western Medicine for diagnosis and treatment of digestive system tumor, Youdian Road 54\#, Hangzhou, 310006, Zhejiang, China. Tel: \\ +86-571-87070965; Fax: +86-571-87070965; E-mail: lhcid21@163.com \\ (c) Ivyspring International Publisher. This is an open access article distributed under the terms of the Creative Commons Attribution (CC BY-NC) license \\ (https://creativecommons.org/licenses/by-nc/4.0/). See http://ivyspring.com/terms for full terms and conditions.
}

Received: 2017.04.02; Accepted: 2017.08.14; Published: 2017.10.19

\begin{abstract}
Trametes robiniophila Murr. (Huaier) is a widely used anti-cancer agent in China. Strong evidence for the anti-proliferative activity of Huaier has been reported; however, its anti-metastatic potential against gastric cancer (GC) as well as its underlying mechanism of action are unknown. Here, we show that treatment with an aqueous Huaier extract over a range of concentrations significantly suppressed both the invasiveness and migratory ability of GC cells. Huaier could also partly reverse the epithelial-mesenchymal transition (EMT), as characterized by increased expression of the epithelial marker E-cadherin and decreased expression of the mesenchymal markers $\mathrm{N}$-cadherin and vimentin. In addition, Huaier-treated cells expressed lower levels of Twist compared to untreated controls, and overexpression of Twist via transfection could partially abolish the anti-metastatic activity of Huaier. Furthermore, elevated Twist expression was correlated with an advanced TNM stage, a high rate of lymph node metastasis, and reduced disease-free survival in GC patients. These findings reveal a novel anti-metastatic mechanism for Huaier, which inhibits the EMT by targeting Twist, suggesting its potential application against a GC relapse.
\end{abstract}

Key words: gastric cancer, Huaier, metastasis, epithelial-mesenchymal transition.

\section{Introduction}

Gastric cancer (GC) is a major health problem and the second biggest cause of cancer-related mortality worldwide ${ }^{[1]}$. Approximately $60 \%$ of all GC cases are diagnosed in Asia ${ }^{[2]}$; however, China has the most cases, accounting for $42 \%$ of all cases worldwide ${ }^{[3]}$. Despite improvements in surgical techniques and adjuvant therapy, GC is still highly lethal, with a 5-year survival rate in China of only $42 \%\left[{ }^{4]}\right.$. Distinctive capabilities that enable tumor growth and metastatic dissemination constitute the major hallmarks of cancer. Until now, most landmark studies of GC treatment have focused on anti-proliferative or anti-angiogenic agents $[5,6]$; few have focused on anti-metastatic drugs. Metastasis is one feature of GC that contributes to poor patient survival. Therefore, it is important to improve our understanding of metastatic mechanisms, and to identify novel therapeutic agents targeting metastasis.

Traditional Chinese medicines (TCMs) that can preferentially kill cancer cells and inhibit metastasis without significant toxicity are an important avenue to explore in cancer therapy. A number of valuable TCMs have been applied as alternative or complementary medicines in the United States and 
Europe. Trametes robiniophila Murr. (Huaier) is a fungus found in China that been used in TCM for approximately 1,600 years. The effective ingredients have been extracted and analyzed by high-performance liquid chromatography and sodium dodecyl sulfate polyacrylamide gel electrophoresis. Proteoglycans were identified as the major components of an aqueous Huaier extract, which consisted of $41.53 \%$ polysaccharides, $12.93 \%$ amino acids, and $8.72 \%$ water ${ }^{[7]}$. In recent years, a wide range of anti-cancer functions have been reported for Huaier, including the induction of apoptosis and anti-angiogenesis, without obvious side effects. Many clinical applications have shown that Huaier has satisfactory therapeutic effects in the treatment of solid malignancies, including liver cancer ${ }^{[8]}, \mathrm{GC}^{[9]}$, cervical cancer ${ }^{[10]}$, breast cancer ${ }^{[11]}$, and lung cancer[12]. Due to this therapeutic significance, the potential molecular targets and mechanisms of Huaier action have received considerable interest ${ }^{[13]}$. Previously, we found that Huaier was able to inhibit the proliferation of GC cell lines and to induce cell apoptosis by activating pro-apoptotic members of the Bcl-2 protein family. Moreover, we showed that Huaier could induce cytotoxicity through the PI3K/AKT signaling pathway[9].

Anti-proliferative activity alone is not sufficient to explain the effects of Huaier in cancer treatment; an anti-metastatic activity may be an important contributor. In vitro and in vivo studies have shown that Huaier can inhibit the invasiveness and metastasis of human hepatocellular carcinoma ${ }^{[14]}$. It is thus of great clinical value to better understand the anti-metastatic potential and cellular mechanism of Huaier action in GC. In the present study, we asked whether Huaier could suppress GC cell metastasis. Increasing evidence indicates that aberrant activation of the embryonic epithelial-mesenchymal transition (EMT) plays a key role in tumor cell invasion and metastasis. Accordingly, the molecular mechanism by which Huaier reduces tumor metastasis was also addressed, in the context of the EMT.

\section{Materials and Methods}

\section{Chemicals and materials}

Aqueous Huaier extract was purchased from Gaitianli Pharmacy Co., Ltd. (Qidong, China). A total of $1 \mathrm{~g}$ electuary ointment was dissolved in $10 \mathrm{ml}$ complete medium and sterilized with a $0.22-\mathrm{mm}$ filter to obtain the $100 \mathrm{mg} / \mathrm{ml}$ stock solution, which was stored at $20^{\circ} \mathrm{C}$ in RPMI-1640 medium (Gibco ${ }^{\circledR}$, Hangzhou MultiSciences Biotech Co., Ltd., Hangzhou, China). Fresh dilutions in medium were made for each experiment. Fetal bovine serum (FBS) was provided by Gibco. Primary antibodies, including E-cadherin, N-cadherin, vimentin, twist, snail, ZEB1 and GAPDH were purchased from Abcam (Cambridge, UK).

\section{Cell lines and transfection}

The SGC7901 and MGC803 human GC cell lines were obtained from the Cell Bank of the Chinese Academy of Sciences (Shanghai, China). The two cell lines were cultured in RPMI-1640 medium supplemented with $10 \% \mathrm{FBS}, 100 \mathrm{U} / \mathrm{ml}$ penicillin and $100 \mu \mathrm{g} / \mathrm{ml}$ streptomycin at $37^{\circ} \mathrm{C}$ in a humidified atmosphere with $5 \% \mathrm{CO} 2$. The cells were subcultured every 2 days. Full length human twist gene was amplified and cloned into a pcDNA3.1(-) vector (Invitrogen, CA) as described previously[15]. Plasmids were transfected into cells with lipofectamine 2000 (Invitrogen, CA).

\section{Total RNA extraction, reverse transcription and $q R T-P C R$}

Total RNA from cells was extracted using Trizol reagent (Invitrogen, CA). Reverse transcription for mRNAs was performed using the M-MLV Reverse Transcriptase (TaKaRa, Dalian, China). The cDNA template was amplified by qRT-PCR using the SYBR® Premix Dimmer Eraser kit (TaKaRa, Dalian, China). GAPDH was used as an internal control to normalize target mRNA level. qRT-PCR reactions were performed by the ABI7500 system (Applied Biosystems, CA). The relative expression fold change of mRNAs was calculated by the $2-\Delta \Delta \mathrm{Ct}$ method. Primers were listed in Table S1.

\section{Western Blot analysis}

Proteins from GC cell lines were extracted with RIPA (Beyotime, Shanghai, China), separated by $8 \%-12 \%$ NUPAGE bis-tris Gel (Invitrogen, CA) and transferred onto polyvinylidene difluoride membranes. The following process was finished as decribed ${ }^{[16] .}$

\section{Invasion assay}

Cell-invasion assay was performed using a transwell assay (Millipore, Billerica, MA). The details of this method have been described [15]. The number of cells placed in the upper chamber was $3 \times 10^{4}$. The stained cells were counted under an inverted microscope (5 fields per membrane). Each experiment was performed in triplicate.

\section{Wound healing assay}

Cells $\left(5 \times 10^{6}\right)$ were implanted onto a 6-well plate. When cells grew to $80 \%$ confluence, the cell monolayer was wounded with a $10 \mu \mathrm{L}$ plastic pipette tip. The remaining cells were incubated at normal 
culture medium. At the indicated times, migrating cells at the wound front were photographed and the percentage of the cleaned area at each time point compared with time 0 was measured using Image-Pro Plus version 6.2 software.

\section{In vivo assays for metastasis in zebrafish}

GC cells were labeled with CM-Dil (Thermo Fisher Scientific, Waltham, MA) using the manufacturer's protocol then washed in phosphate-buffered saline and resuspended at 10,000 cells $/ \mathrm{mL}$. Zebrafish embryos at $48 \mathrm{~h}$ post-fertilization were anesthetized by placement in $0.04 \mathrm{mg} / \mathrm{mL}$ of ethyl 3-aminobenzoate methanesulfonate (tricaine). CM-Dil cells (100 cells in $10 \mathrm{~nL} ; 30 \mathrm{~nL}$ injection volume per embryo) were injected with a pneumatic picopump injector using glass microinjection needles. Groups of larvae (30) with red fluorescence at the injection site were moved to 6-well plates (30 embryos per well). Larvae were treated at 8 days post-injection (dpi) and incubated at $35^{\circ} \mathrm{C}$ during treatment.

Stock solutions of Huaier to be tested were made at a $100 \times$ working concentration in an appropriate solvent. Huaier was then diluted to the final concentration with E3 medium. Fresh drug-containing E3 medium was replaced daily; E3 medium alone was used on untreated controls. We evaluated tumor growth and metastasis in injected zebrafish larvae every $2 \mathrm{dpi}$ by fluorescence microscopy. Images were captured on a Nikon SMZ1500 microscope, and the distance of metastatic spread was measured using NIS-Elements D 3.10 software. The relative distance of metastasis was calculated using the following formula: relative distance $=$ distance at each point $/$ distance at $0 \mathrm{dpi}$.

\section{Immunofluorescence}

Cell $\left(5 \times 10^{3}\right)$ were implanted onto a cell culture dish (NEST Biotech, Hong Kong) for 24 hours. Cells were fixed with paraformaldehyde for 30 minutes, then permeabilized with $0.1 \%$ Triton X-100 for $5 \mathrm{~min}$ at room temperature, the primary antibodies was added after permeabilization, After incubation in the dark for 24 hours at $4^{\circ} \mathrm{C}$, cells were incubated with alexa flours $488 \mathrm{TgG}$ donkey anti-mouse or anti-rabbit (1:500, Invitrogen, USA) for an hours at room temperature, Nuclei were stained with propidium iodide (PI) for 5 minutes when necessary. Fluorescence images were photographed with a confocal microscopy (Leica DMIRE2, Germany).

\section{Immunohistochemistry (IHC)}

GC tissues were fixed in $10 \%$ formalin and embedded in paraffin sample. After soaking in xylene to dewax and hydrating with an ethanol gradient, the slices were deactivated the endogenous peroxidase through incubating with $3 \% \mathrm{H}_{2} \mathrm{O}_{2}$ at room temperature for $5 \mathrm{~min}$ and washed with PBS. Next, the antigens were recovered with citrate buffer $(0.01$ $\mathrm{M}, \mathrm{pH}$ 6.0), and the non-specific antigens were blocked at room temperature for $10 \mathrm{~min}$ using $5 \%$ normal goat serum. The rabbit anti-human twist monoclonal antibody was added and the slices were incubated at $4^{\circ} \mathrm{C}$ overnight and washed with PBS. Then, added the biotin-labeled secondary antibody [donkey anti-rabbit IgG polyclonal antibody, biotin conjugated (Abcam company, Cambridge, British; 1:200 dilution)], and incubated the slices at $37^{\circ} \mathrm{C}$ for 1 $\mathrm{h}$, followed by a PBS wash. Added HRP-conjugated streptavidin working solution on the slices and washed them with PBS. After stained with DAB and mildly stained with hematoxylin for 10-15 min, the slices were soaked in an alcohol solution with hydrochloric acid and dilute ammonia for several minutes. The slices were then dehydrated with the gradient alcohol solutions and mounted in neutral balsam. IHC staining was scored independently by two pathologists and interpreted according to the guidelines published in the previous study. we scored the positive staining results in categories from 0 to $3+$ as follows: 0 , no staining; $1+, 1-25 \%$ of the specimen stained; $2+, 26-50 \%$; and $3+,>50 \%$. A score of $2+$ and $3+$ was considered to be a positive IHC result.

\section{Statistical analysis}

Comparisons of continuous data were analyzed by the independent $t$ test between the 2 groups, whereas categorical data were analyzed by the chi-square test. Disease-free survival was analyzed by the Kaplan-Meier method. All statistical analyses were performed using SPSS for Windows v.16.0 (SPSS, Chicago, IL) and GraphPad Prism 5.0 (GraphPad Software, La Jolla, CA). P $<0.05$ was considered statistically significant.

\section{Results}

\section{Huaier suppressed the migration and invasiveness of $\mathbf{G C}$ cells}

We determined whether Huaier could alter invasiveness and migration using Transwell and wound-healing assays. SGC7901 cells were incubated in media containing different concentrations of Huaier $(0,0.1,0.2,0.3$, and $0.5 \mathrm{mg} / \mathrm{mL})$ for $24 \mathrm{~h}$ and $48 \mathrm{~h}$ before the Transwell assays. Huaier at these concentrations produced no inhibitory effects on cell growth. The Transwell assays showed that significantly fewer Huaier-treated SGC7901 cells had moved into the lower compartment of the migration chamber after both 24 and $48 \mathrm{~h}$ when compared to untreated control cells (Figure 1A and B). Huaier also 
inhibited invasiveness in a dose-dependent manner. In wound-healing assays, microscopic examination at both 12 and $24 \mathrm{~h}$ revealed a significant delay in wound closure by SGC7901 cells after treatment with Huaier (Figure 1C). Transwell and wound-healing

\section{A}

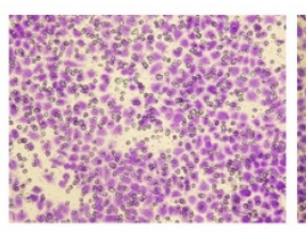

control

B

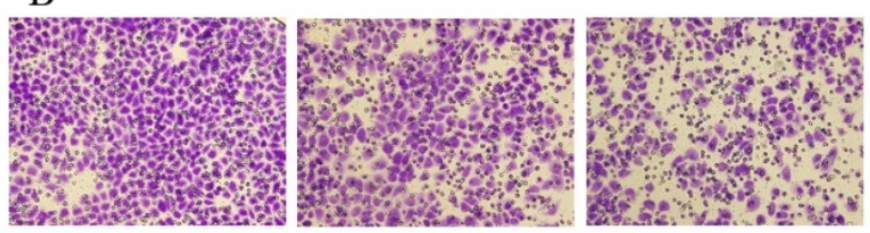

$\mathrm{C}$
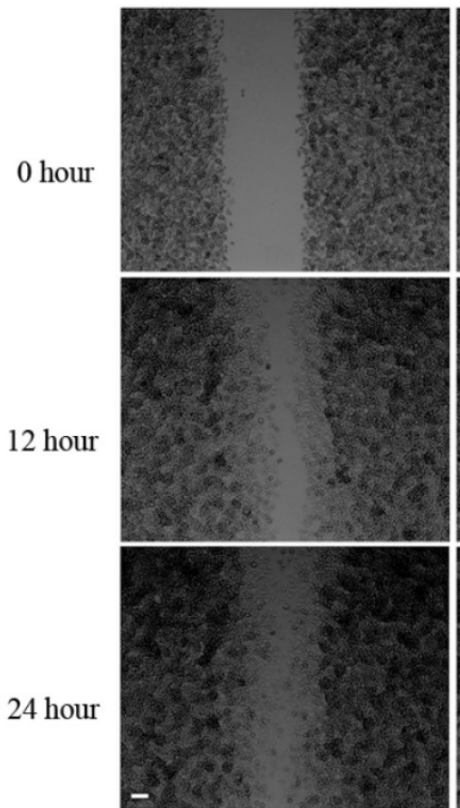

control
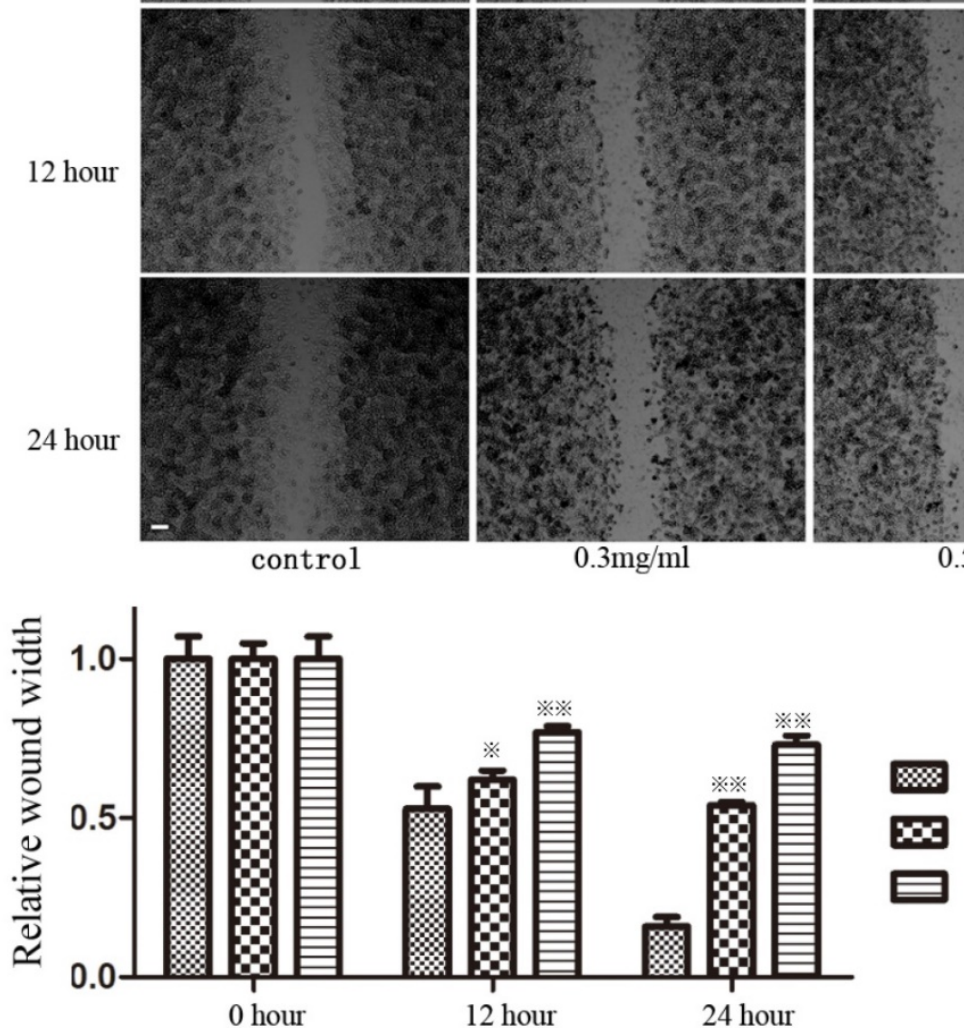

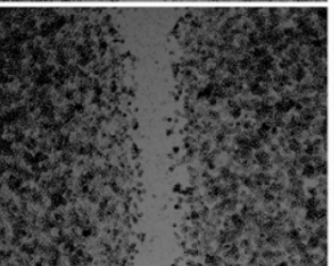

$0.3 \mathrm{mg} / \mathrm{ml}$ assays also confirmed that Huaier suppressed the migration and invasiveness of another GC cell line, MGC803 (data not shown, Supplementary Figure 1).

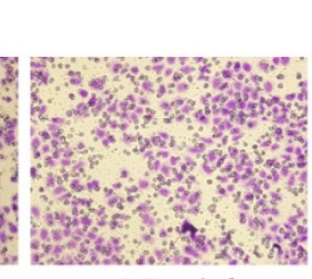

$0.5 \mathrm{mg} / \mathrm{ml}$
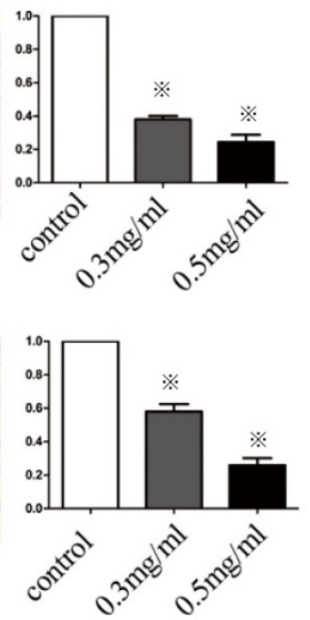
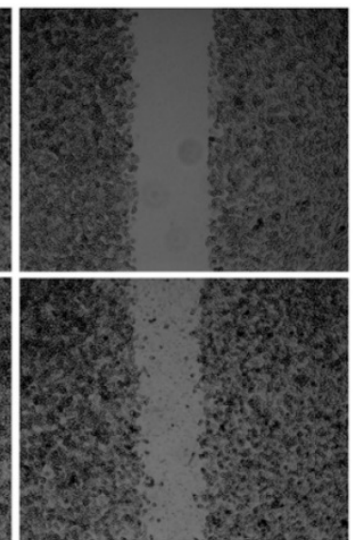

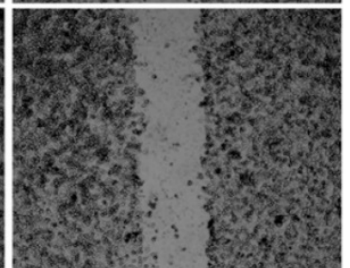

$0.5 \mathrm{mg} / \mathrm{ml}$ control

$0.3 \mathrm{mg} / \mathrm{ml}$

$0.5 \mathrm{mg} / \mathrm{ml}$

Figure 1. Invasiveness and migratory ability of SGC7901 cells after treatment with Huaier. (A) The invasiveness of SGC7901 cells after treatment with Huaier at different concentrations was evaluated in Transwell assays at $24 \mathrm{~h}(\mathrm{~B})$ and $48 \mathrm{~h}(\mathrm{C})$. The migratory ability of SGC7901 cells after treatment with Huaier at

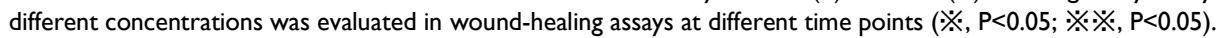




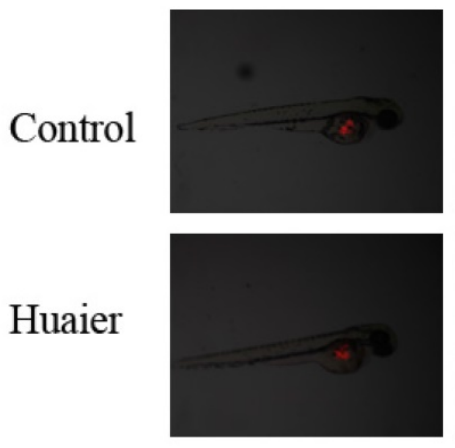

0dpi
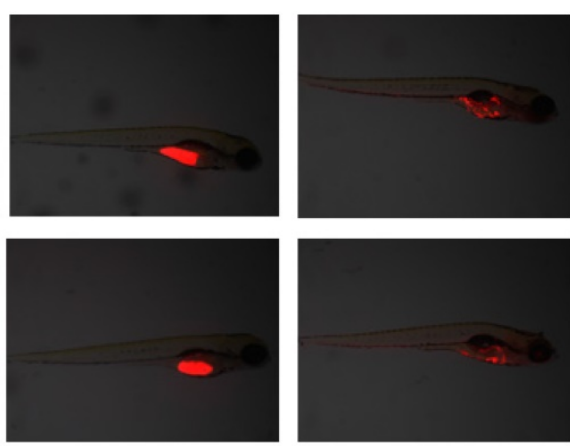

2dpi

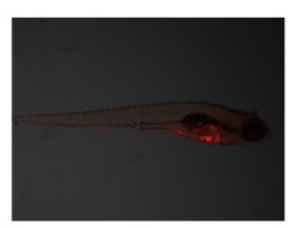

4dpi
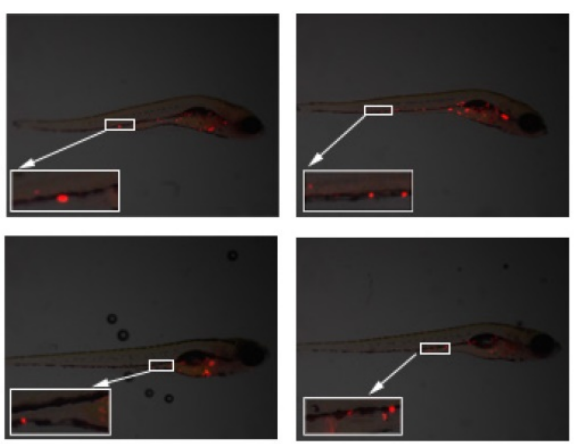

6dpi

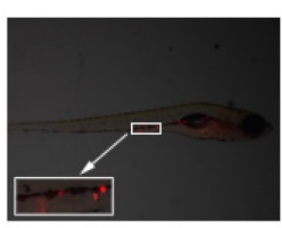

8dpi

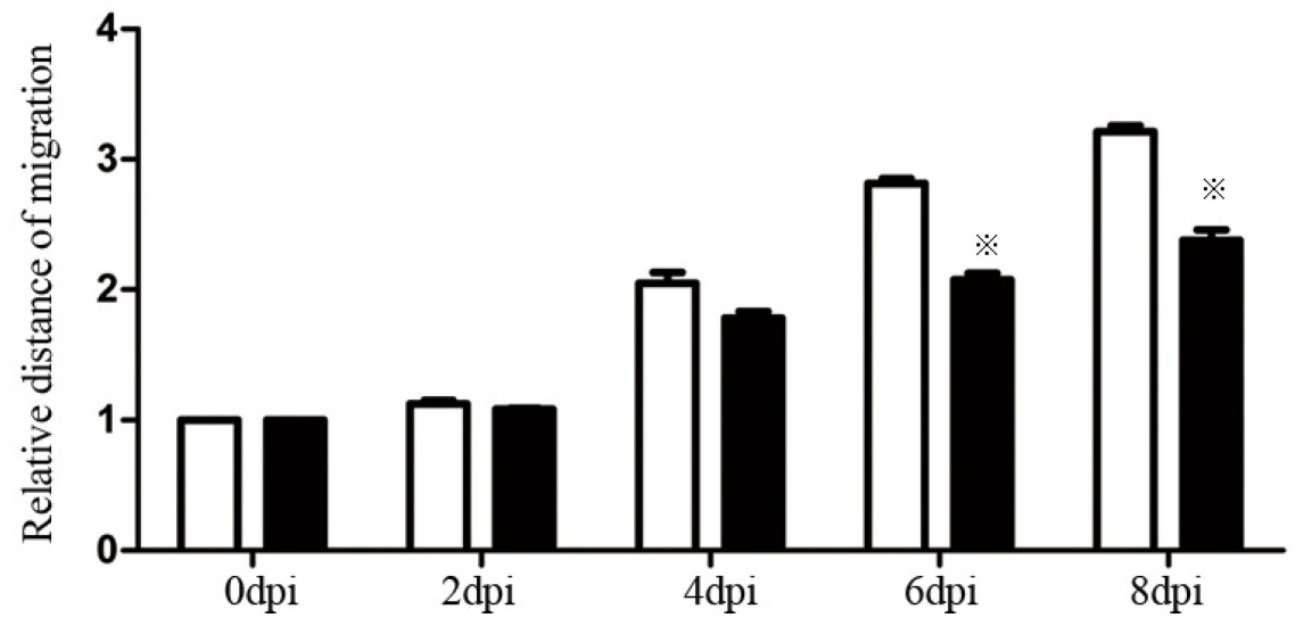

$\square$ Control

Huaier

Figure 2. Anti-metastatic effects of Huaier, evaluated in vivo in zebrafish.

We labeled cells with CM-Dil and injected them into zebrafish embryos to look at the anti-metastatic effects of Huaier in vivo. As shown in Figure 2, SGC7901 cells labeled with CM-Dil migrated to the edge of the embryonic yolk sac in both groups, but the relative distance of metastasis in the Huaier-treated group was markedly shorter at 6 and 8 dpi than in the control group. These results indicate the anti-metastatic activity of Huaier in zebrafish embryos.

\section{Huaier reversed the EMT in GC cells}

The EMT plays an important role in promoting invasion. To explore the potential mechanisms by which Huaier reduced metastasis in GC cells, we treated SGC7901 cells with Huaier for $24 \mathrm{~h}$ at 0.5 $\mathrm{mg} / \mathrm{mL}$, and then examined their expression of epithelial and mesenchymal markers. As shown in Figure 3, we observed increased expression of epithelial markers, including E-cadherin, and decreased expression of the mesenchymal markers $\mathrm{N}$-cadherin and vimentin. In addition, reduced fluorescence intensity, reflecting the F-actin content, was observed with Huaier treatment.

\section{Huaier treatment reduced the Twist expression level}

Because a series of transcription factors (TFs) are involved in regulating the EMT, we assessed the effect of Huaier on the expression of the following TFs known to promote the EMT: Snai1 (Snail), Snai2 (Slug), Twist1 (Twist), Forkhead box C1 (FOXC1), and zinc finger E-box-binding homeobox 1 (Zeb1). Huaier-treated cells expressed remarkably less Twist compared with control cells. The expression levels of Snail, FOXC1, Slug, and Zeb1, however, remained unchanged (Figure 4). This suggests that Huaier regulates the EMT via decreased Twist expression.

\section{Twist overexpression partly abolished the anti-metastatic activity of Huaier, and induced the EMT in GC cells}

We next examined whether Huaier suppresses GC metastasis by decreasing Twist. SGC7901 cells were transfected with pcDNA3.1(-)-twist or pcDNA3.1(-) control. Western blots were used to confirm these transfections (Figure $4 \mathrm{C}$ ). At $48 \mathrm{~h}$ after transfection, both groups of cells were treated with Huaier for $24 \mathrm{~h}$ at $0.5 \mathrm{mg} / \mathrm{mL}$, and then examined for invasion ability using Transwell assays. The results show that GC invasiveness, suppressed by treatment 
with Huaier, was partly restored by exogenous Twist expression (Figure 5A and B).

We further examined whether the expression of E-cadherin and vimentin, both of which were significantly affected by Huaier treatment, could be regulated by Twist in SGC7901 cells. Transient transfection with pcDNA3.1(-)-twist resulted in decreased expression of E-cadherin and increased expression of vimentin (Figure 5C). Taken together, these lines of evidence demonstrate that Huaier could reverse the EMT in a Twist-dependent manner.

\section{Twist was highly expressed in GC tissues and was correlated with cancer relapse}

To explore the therapeutic value of Huaier in GC

A

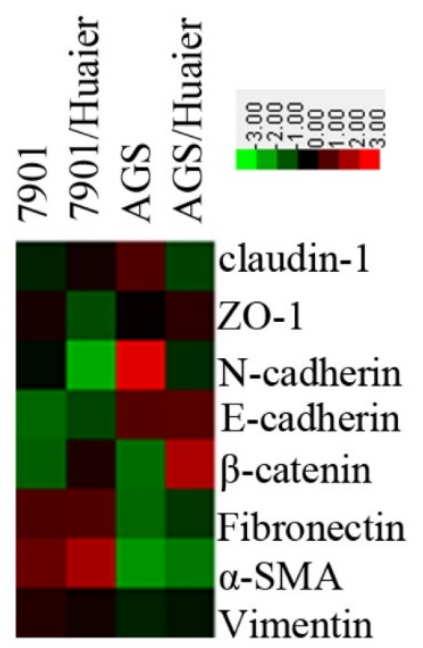

patients, we asked whether Twist expression was increased in tumors. We examined tissues from 74 GC patients (Figure 6A-D). Among all cases, 27 (33.8\%) were Twist-negative (0 to $1+)$ and $47(66.2 \%)$ were positive $(2+$ to $3+)$; of these, 18 cases $(64.2 \%)$ were positive $(++)$ and $29(35.8 \%)$ were strongly positive $(+++)$. The positive expression level of Twist in GC tissues was significantly correlated with advanced TNM stage $(\mathrm{P}=0.044)$ and with a high rate of lymph node metastasis $(\mathrm{P}=0.002)$. There was no significant correlation between Twist expression and sex, age, tumor location, tumor size, Lauren's classification, or serum CEA level (Table 1).

C
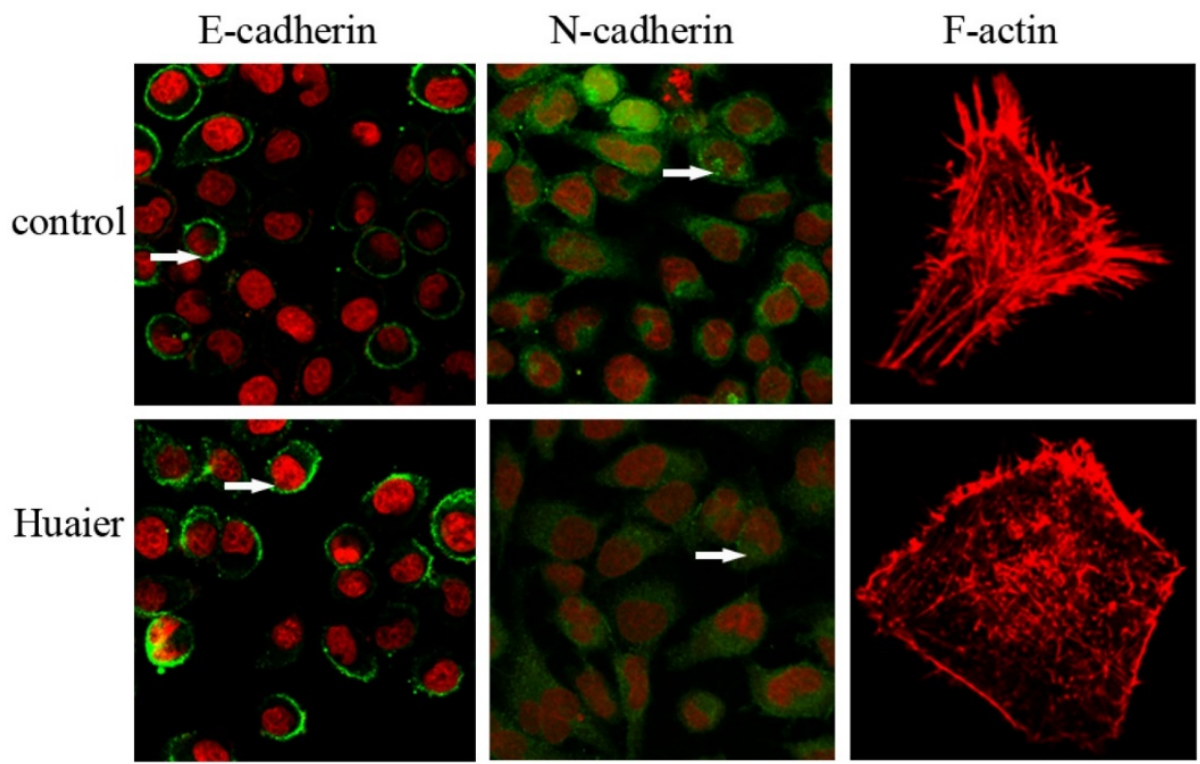

Figure 3. Effect of Huaier on the expression of epithelial and mesenchymal markers. (A) A heat map representing the mRNA expression levels of epithelial and mesenchymal markers. (B) Western blot assays of the expression levels of epithelial and mesenchymal markers after treatment with Huaier. (C) Confocal microscopic analysis of phenotypic markers, including E-cadherin, $\mathrm{N}$-cadherin, and F-actin. The green signal represents staining for the corresponding proteins, red represents nuclear DNA staining by DAPI, and a white arrow indicates specifically stained cells. 

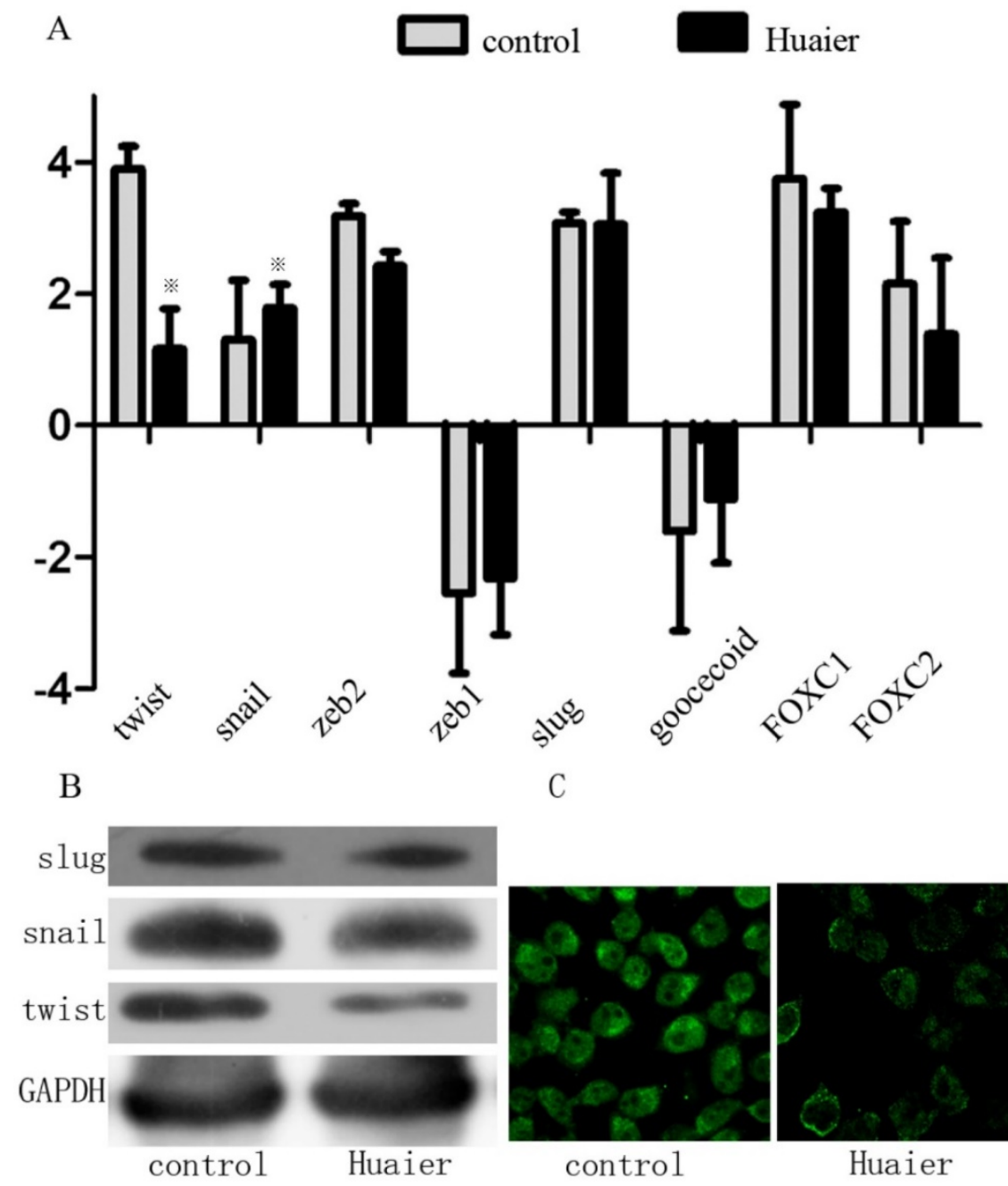

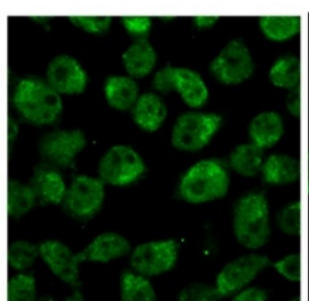

control

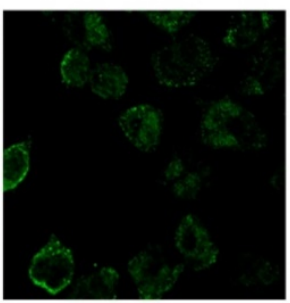

Huaier

Figure 4. Effect of Huaier on the expression of EMT-related TFs. (A) Expression of EMT-related TFs as measured by real-time RT-PCR in Huaier-treated SGC7901 cells and untreated control cells. (B) EMT-related TFs (Snail, Slug, and Twist) were analyzed by Western blotting in Huaier-treated SGC7901 cells and control cells. (C) Twist expression was examined by confocal microscopy $(※, \mathrm{P}<0.05)$.

The 3- and 5-year cumulative disease-free survival (DFS) rates were $29 \%$ and $23 \%$, respectively, for patients with high Twist expression, and $75 \%$ and $55 \%$, respectively, for those with low Twist expression (Figure 6E and F). A univariate analysis indicated that the factors associated significantly with survival were microvascular invasion, invasion depth, lymph node metastasis, TNM stage, and Twist level (Table 2). The clinicopathological parameters that were correlated with patient survival in the univariate analysis were included in a multivariate Cox analysis. The results show that TNM stage and Twist expression were independent prognostic factors for DFS after surgery (Table 2).

\section{Discussion}

Migration and proliferation are key events in cancer progression; the underlying molecular mechanisms of these processes have been the focus of much investigation, which has led to the emergence of possible treatment options. Huaier, one of the main active components of the dried roots of Sophora flavescence, has long been used to treat cancer in China. We previously reported the anti-proliferative, apoptosis-inducing activity of Huaier in hepatocellular carcinoma and GC cells. Our results showed that Huaier was able to inhibit the viability of tumor cells in a dose-dependent manner, inducing tumor cell apoptosis by increasing pro-apoptotic Bcl-2 family proteins ${ }^{[9]}$. However, metastasis is the most important cause of mortality from cancer, and it represents one of the main obstacles to improving the prognosis in GC. Thus, our ability to effectively treat GC is largely dependent on our capacity to limit metastasis. In the present study, we explored the functional role of Huaier in reducing GC cell metastasis. We employed Transwell and wound-healing assays to determine whether Huaier could inhibit the migration and invasiveness of GC cells. In vitro and in vivo assays showed that Huaier 
treatment of SGC7901 cancer cells significantly reduced invasion and migration. This anti-migration effect in GC cells is in agreement with the findings of earlier reports demonstrating that Huaier could inhibit invasion by ovarian cancer cells ${ }^{[7]}$.

Table 1: The relationship between Twist expression and clinicopathological feature of 74 GC patients

\begin{tabular}{|c|c|c|c|c|c|}
\hline \multirow[t]{2}{*}{$\begin{array}{l}\text { Clinicopatholocical } \\
\text { variables }\end{array}$} & \multirow{2}{*}{$\begin{array}{l}\text { Number } \\
\text { of each } \\
\text { group }\end{array}$} & \multicolumn{2}{|c|}{$\begin{array}{l}\text { Twist } \\
\text { expression }\end{array}$} & \multirow[t]{2}{*}{$\mathrm{X} 2$} & \multirow[t]{2}{*}{$\mathrm{P}$ value } \\
\hline & & high & low & & \\
\hline All case & 74 & 47 & 27 & & \\
\hline \multicolumn{6}{|l|}{ Age(years) } \\
\hline$\leqq 50$ & 28 & 29 & 17 & 0.012 & 0.914 \\
\hline$>50$ & 46 & 18 & 10 & & \\
\hline \multicolumn{6}{|l|}{ gender } \\
\hline Male & 50 & 33 & 17 & 0.411 & 0.521 \\
\hline female & 24 & 14 & 10 & & \\
\hline \multicolumn{6}{|l|}{ HP } \\
\hline positive & 51 & 35 & 16 & 1.852 & 0.174 \\
\hline negative & 23 & 12 & 11 & & \\
\hline \multicolumn{6}{|l|}{ Size of tumor, $(\mathrm{cm})$} \\
\hline$<5($ small $)$ & 39 & 24 & 15 & 0.139 & 0.709 \\
\hline$\geqq 5$ (large) & 35 & 23 & 12 & & \\
\hline Location of tumor & & & & 0.256 & 0.880 \\
\hline Cardia & 16 & 11 & 5 & & \\
\hline Body & 19 & 12 & 7 & & \\
\hline antrum & 39 & 24 & 15 & & \\
\hline $\begin{array}{l}\text { Depth of tumor } \\
\text { invasion }\end{array}$ & & & & 3.12 & 0.374 \\
\hline $\mathrm{T} 1$ & 11 & 5 & 6 & & \\
\hline $\mathrm{T} 2$ & 6 & 4 & 2 & & \\
\hline T3 & 21 & 16 & 5 & & \\
\hline $\mathrm{T} 4$ & 36 & 22 & 14 & & \\
\hline $\begin{array}{l}\text { Lymph node } \\
\text { metastasis }\end{array}$ & & & & 16.465 & 0.002 \\
\hline No & 9 & 2 & 7 & & \\
\hline N1 & 8 & 2 & 6 & & \\
\hline N2 & 29 & 20 & 9 & & \\
\hline N3 & 28 & 23 & 5 & & \\
\hline vessel invasion & & & & 0.739 & 0.373 \\
\hline Negative & 51 & 32 & 21 & & \\
\hline positive & 21 & 15 & 6 & & \\
\hline Stage & & & & 4.054 & 0.044 \\
\hline $\mathrm{I}, \mathrm{II}$ & 20 & 9 & 11 & & \\
\hline III,IV & 54 & 38 & 16 & & \\
\hline Lauren's classification & & & & 0.126 & 0.723 \\
\hline diffuse & 21 & 14 & 7 & & \\
\hline intestinal & 53 & 33 & 20 & & \\
\hline $\begin{array}{l}\text { Grade of } \\
\text { differentiation }\end{array}$ & & & & 0.152 & 0.696 \\
\hline Well and moderate & 24 & 16 & 8 & & \\
\hline Poor and not & 50 & 31 & 19 & & \\
\hline $\begin{array}{l}\text { Preoperative } \\
\text { chemotherapy }\end{array}$ & & & & 0.412 & 0.521 \\
\hline Yes & 31 & 21 & 10 & & \\
\hline no & 43 & 26 & 17 & & \\
\hline $\begin{array}{l}\text { Serum CEA } \\
\text { value(ug/L) }\end{array}$ & & & & 0.216 & 0.642 \\
\hline$<25$ & 44 & 27 & 10 & & \\
\hline$\geqq 25$ & 30 & 20 & 17 & & \\
\hline $\begin{array}{l}\text { Serum CA199 } \\
\text { value(ug/L) }\end{array}$ & & & & 0.498 & 0.481 \\
\hline$<25$ & 54 & 33 & 21 & & \\
\hline$\geqq 25$ & 20 & 14 & 6 & & \\
\hline
\end{tabular}

Table 2: Univariate and multivariate analyses of factors associated with 5-year DFS

\begin{tabular}{|c|c|c|c|c|}
\hline \multirow[t]{2}{*}{ Clinicopatholocical variables } & \multicolumn{4}{|c|}{ Univariate multivariate } \\
\hline & $\mathrm{P}$ & HR value & $95 \% \mathrm{CI}$ & $\mathrm{P}$ \\
\hline Age(years): $\leqq 50$ versus $>50$ & 0.519 & & & NA \\
\hline Gender: male versus female & 0.741 & & & NA \\
\hline HP: positive versus negative & 0.917 & & & NA \\
\hline Size: $<5 \mathrm{~cm}$ versus $\geqq 5 \mathrm{~cm}$ & 0.470 & & & NA \\
\hline $\begin{array}{l}\text { Location: cardia versus body } \\
\text { versus antrum }\end{array}$ & 0.601 & & & NA \\
\hline $\begin{array}{l}\text { Invasion depth: } \mathrm{T} 1 \text { versus } \mathrm{T} 2 \\
\text { versus } \mathrm{T} 3 \text { versus } \mathrm{T} 4\end{array}$ & 0.039 & 1.080 & $0.651-1.789$ & 0.767 \\
\hline $\begin{array}{l}\text { LNM: N0 versus N1 versus N2 } \\
\text { versus N3a versusN3b }\end{array}$ & 0.011 & 1.078 & $0.765-1.518$ & 0.669 \\
\hline Twist: high versus low & 0.001 & 0.407 & $0.184-0.898$ & 0.026 \\
\hline $\begin{array}{l}\text { Microvessel invasion: yes } \\
\text { versus no }\end{array}$ & 0.046 & 1.618 & $0.859-3.051$ & 0.137 \\
\hline Stage I,II versus Stage III,IV & $<0.001$ & 4.433 & $1.579-20.762$ & 0.039 \\
\hline $\begin{array}{l}\text { Lauren's classification: diffuse } \\
\text { versus intestinal }\end{array}$ & 0.850 & & & NA \\
\hline $\begin{array}{l}\text { Grade of differentiation: Well } \\
\text { and moderate versus Poor and } \\
\text { not }\end{array}$ & 0.536 & & & NA \\
\hline $\begin{array}{l}\text { Preoperative chemotherapy: } \\
\text { yes versus no }\end{array}$ & 0.080 & & & NA \\
\hline CEA (ug/L): $\leqq 50$ versus $>50$ & 0.474 & & & NA \\
\hline CA199 (ug/L): $\leqq 50$ versus $>50$ & 0.554 & & & NA \\
\hline
\end{tabular}

The ability of Huaier to suppress metastasis calls for additional studies to identify its role in the context of the EMT. Mounting evidence has demonstrated that the acquisition of invasive characteristics by tumors is associated with the ability of tumor cells to undergo the EMT[17], which is characterized by diminished epithelial characteristics and increased mesenchymal attributes. EMT programs are defined by changes in the expression of certain differentiation markers from an epithelial to a mesenchymal pattern, and by functional modifications endowing cells with enhanced migratory/invasive properties ${ }^{[18]}$. Downregulation of E-cadherin and up-regulation of $\mathrm{N}$-cadherin have been reported in various tumors during the EMT[19]. In this study, both real-time RT-PCR and Western blots showed that treatment with Huaier induced the down-regulated expression of $\mathrm{N}$-cadherin and up-regulated expression of E-cadherin. Vimentin, another important mesenchymal marker, is a primary component of the mesenchymal intermediate filament (IF) network. We found significantly reduced expression of vimentin in Huaier-treated cells compared to control cells. In addition to the assembly of the IF network, actin cytoskeleton organization and polymerization contribute to cell migration. We also observed that Huaier treatment resulted in depolymerization of the F-actin cytoskeleton and diminution of the cellular F-actin content. Together, these findings suggest that Huaier suppresses GC cell metastasis by regulating the EMT. 
Currently, the exact mechanism of EMT progression remains largely unexplored. However, the critical role of certain TFs in activating the EMT has been well documented. These TFs include the homeobox protein Goosecoid[20], the zinc-finger proteins Snail and Slug[21, 22], the basic helix-loop-helix protein Twist $[23]$, the forkhead box proteins FOXC1[24, ${ }^{25]}$ and $\mathrm{FOXC2}[26]$, and the zinc-finger, E-box-binding proteins Zeb1 and Sip1 (Zeb2)[27, 28]. Therefore, we assessed the effect of Huaier on the expression of these TFs by real-time RT-PCR and Western blotting, and we found that Huaier-treated cells expressed lower levels of Twist than did control cells. Furthermore, we demonstrated that the anti-invasion effect of Huaier could be abolished by exogenous Twist expression, which can elicit a complete EMT. Taken together, these findings suggest that Huaier could reverse the EMT in GC cells through reduced Twist expression. The mechanism of Twist activation and its upstream signaling pathway has been widely investigated. For example, activation of the PI3K/AKT signaling pathway has been implicated in promoting Twist expression ${ }^{[29]}$. At the same time, we previously showed that Huaier could inhibit GC cell proliferation by reducing the expression of $\mathrm{p}-\mathrm{AKT}$

A

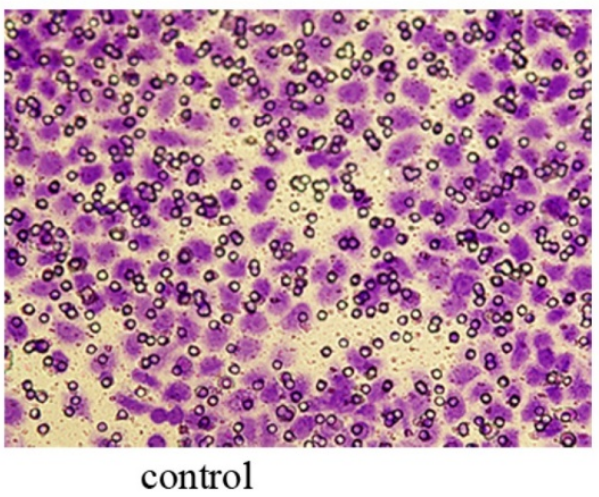

and PI3K[9]. We propose that Huaier regulates Twist expression indirectly, with the involvement of PI3K/AKT signaling. However, our present study failed to provide direct evidence to support this hypothesis. The mechanism underlying decreased Twist expression after Huaier treatment deserves further study.

To explore the potential application of Huaier in the clinical treatment of GC, we investigated Twist levels in tissues from 74 patients with gastric adenocarcinoma by immunohistochemistry (IHC). We found that 47 out of $74(66.2 \%)$ GC tissues showed Twist-positive staining. The Twist IHC score was significantly increased in cancer tissues compared with non-tumor tissues (data not shown). Simultaneously, Twist-positive staining in GC tissues was significantly correlated with an advanced TNM stage and a high rate of lymph node metastasis. Furthermore, we found that elevated Twist expression was correlated with reduced DFS in GC patients. These lines of evidence suggest the participation of Twist in regulating the metastatic process and support the potential use of Huaier in reducing GC relapse.
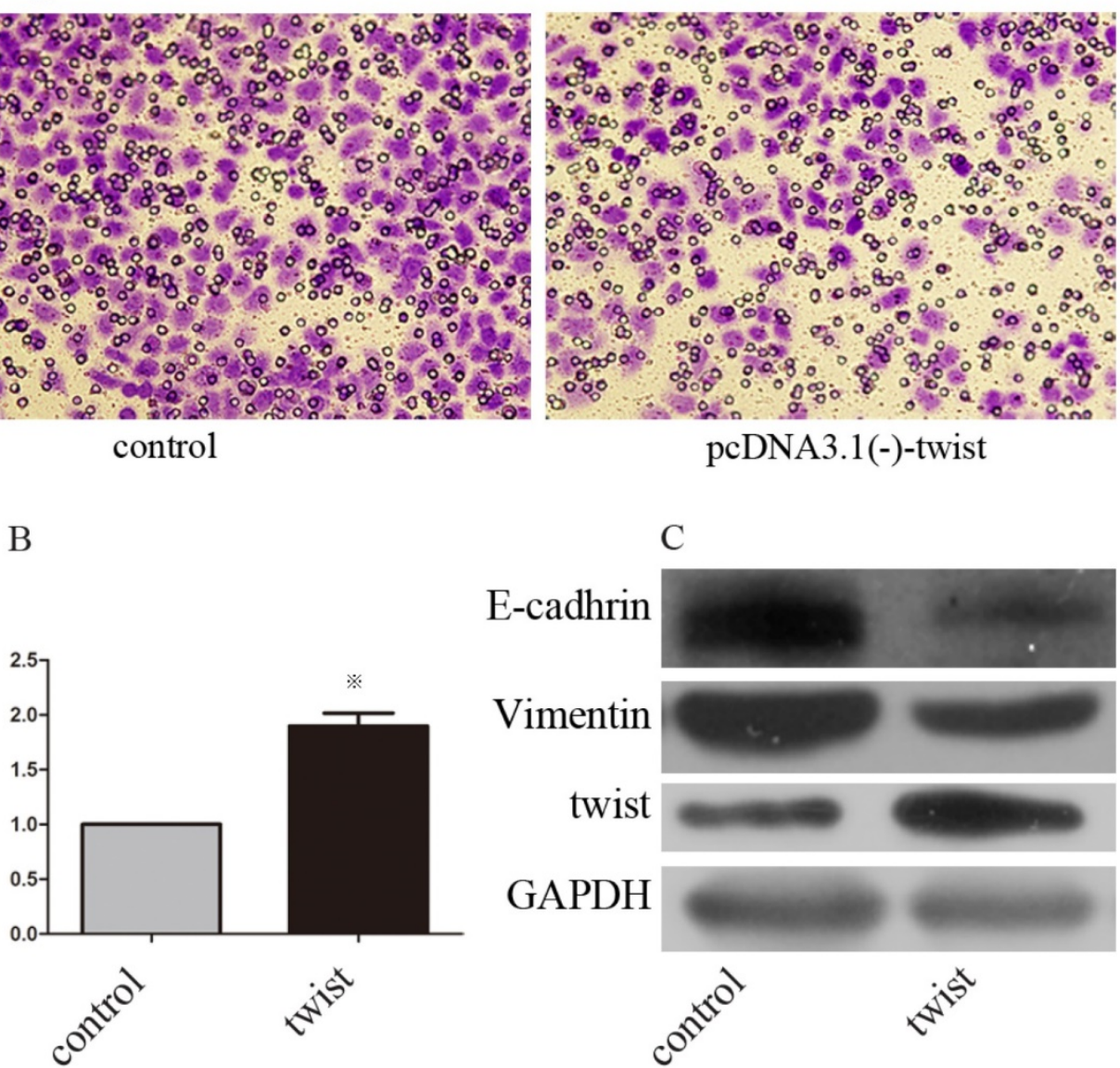

Figure 5: The effect of exogenous twist on EMT and anti-metastasis effect of martrine. (A, B) Altered invasiveness ability was investigated with transwell assays after treatment with martrine for $24 \mathrm{~h}$ at $0.5 \mathrm{mg} / \mathrm{ml},(※, \mathrm{p}<0.05)$. (C) The efficiency of transfections and the altered expression of epithelial and mesenchymal marker after transfection were analyzed with Western-blot. 
A

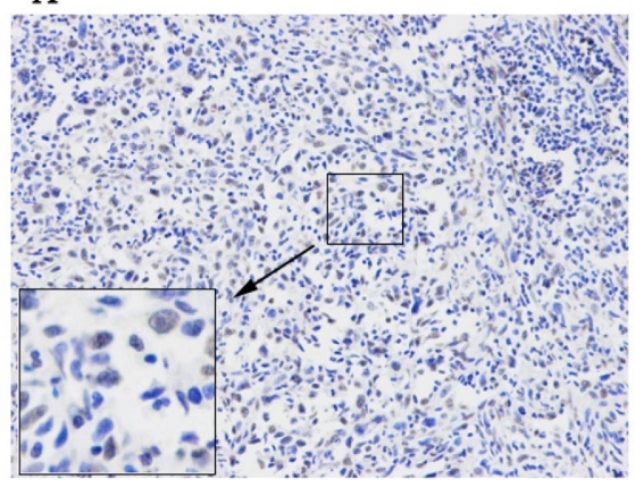

C
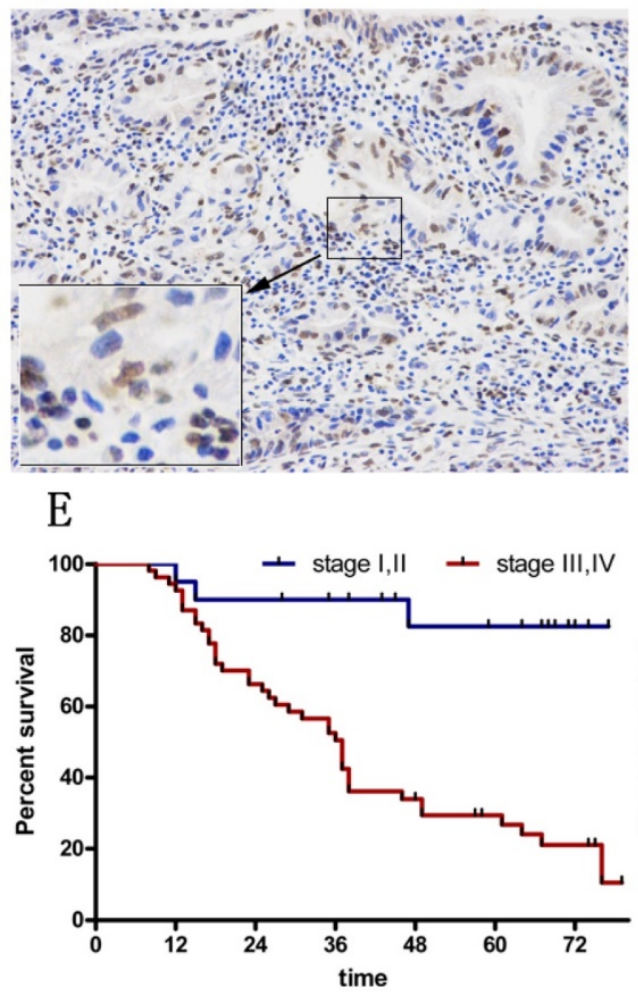

B

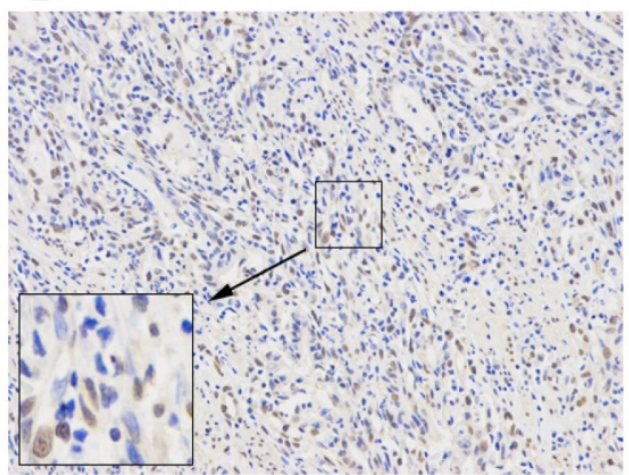

D

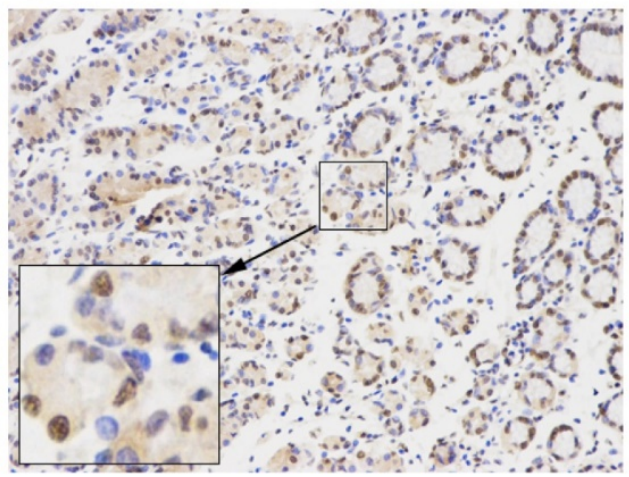

F

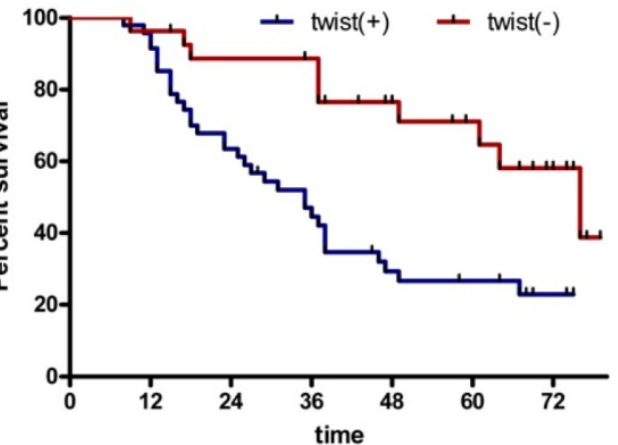

Figure 6: Immunohistochemical staining for twist in gastric cancer tissues. (A) No staining in GC tissues. (B) Weak staining in GC tissues (1+). (C) Moderate staining in GC tissues (2+). (D) Strong staining in GC tissues (3+). Magnification $\times 100$. (E) DFS curves of GC patients according to stage. (F) DFS curves of GC patients according to the twist expression levels.

In conclusion, our results demonstrate that Huaier can inhibit GC cell metastasis in vitro. This inhibitory effect could be achieved by the degradation of Twist, which contributes to both the EMT and metastasis. These results enhance our understanding of the molecular mechanisms involved in the anti-tumor activity of Huaier, increasing its potential for clinical application to reduce the recurrence of GC.

\section{Supplementary Material}

Supplementary figure 1 and table $S 1$.

http://www.jcancer.org/v08p3876s1.pdf

\section{Acknowledgements}

This study was supported by the Zhejiang medical and health science and technology project [Grant No. 2013KYA029, 2016KYB220], Zhejiang provincial natural science foundation [Grant No. LY16H280011], Great Sci-tech Program of Zhejiang Provincial Sci-tech Plan [Grant No. 2013C03044-4] and National natural science foundation of China [Grant No. 81573953]. We thank the surgeons and nurses who kindly facilitate the recruitment and collection of patient information. 


\section{Competing Interests}

The authors have declared that no competing interest exists.

\section{References}

1. Torre LA, Bray F, Siegel RL, Ferlay J, Lortet-Tieulent J, Jemal A. Global cancer statistics, 2012. CA Cancer J Clin. 2015; 65: 87-108.

2. Shen L, Shan YS, Hu HM, et al. Management of gastric cancer in Asia: resource-stratified guidelines. LANCET ONCOL. 2013; 14: e535-e547.

3. Chen W, Zheng R, Baade PD, et al. Cancer statistics in China, 2015. CA Cancer J Clin. 2016; 66: 115-132.

4. Strong VE, Wu AW, Selby LV, et al. Differences in gastric cancer survival between the U.S. and China. J SURG ONCOL. 2015; 112: 31-37.

5. Fuchs CS, Tomasek J, Yong CJ, et al. Ramucirumab monotherapy for previously treated advanced gastric or gastro-oesophageal junction adenocarcinoma (REGARD): an international, randomised, multicentre, placebo-controlled, phase 3 trial. LANCET. 2014; 383: 31-39.

6. Wilke H, Muro K, Van Cutsem E, et al. Ramucirumab plus paclitaxel versus placebo plus paclitaxel in patients with previously treated advanced gastric or gastro-oesophageal junction adenocarcinoma (RAINBOW): a double-blind, randomised phase 3 trial. LANCET ONCOL. 2014; 15: 1224-1235.

7. Yan X, Lyu T, Jia N, Yu Y, Hua K, Feng W. Huaier aqueous extract inhibits ovarian cancer cell motility via the AKT/GSK3beta/beta-catenin pathway. PLOS ONE. 2013; 8: e63731

8. Lei JY, Yan LN, Zhu JQ, Wang WT. Hepatocellular Carcinoma Patients May Benefit From Postoperative Huaier Aqueous Extract After Liver Transplantation. Transplant Proc. 2015; 47: 2920-2924.

9. Xie HX, Xu ZY, Tang JN, et al. Effect of Huaier on the proliferation and apoptosis of human gastric cancer cells through modulation of the PI3K/AKT signaling pathway. EXP THER MED. 2015; 10: 1212-1218.

10. Yan L, Liu X, Yin A, Wei Y, Yang Q, Kong B. Huaier aqueous extract inhibits cervical cancer cell proliferation via JNK/p38 pathway. INT J ONCOL. 2015; 47: 1054-1060.

11. Li Y, Qi W, Song X, Lv S, Zhang H, Yang Q. Huaier extract suppresses breast cancer via regulating tumor-associated macrophages. Sci Rep. 2016; 6: 20049.

12. $\mathrm{Wu} \mathrm{T}$, Chen $\mathrm{W}$, Liu $\mathrm{S}$, et al. Huaier suppresses proliferation and induces apoptosis in human pulmonary cancer cells via upregulation of miR-26b-5p. FEBS LETT. 2014; 588: 2107-2114.

13. Xia Q, Mao W. Anti-tumor effects of traditional Chinese medicine give a promising perspective. J CANCER RES THER. 2014; 10 Suppl 1: 1-2.

14. Li C, Wu X, Zhang H, et al. A Huaier polysaccharide inhibits hepatocellular carcinoma growth and metastasis. Tumour Biol. 2015; 36: 1739-1745.

15. Xu ZY, Ding SM, Zhou L, et al. FOXC1 contributes to microvascular invasion in primary hepatocellular carcinoma via regulating epithelial-mesenchymal transition. INT J BIOL SCI. 2012; 8: 1130-1141.

16. Cheng J, Xie HY, Xu X, et al. NDRG1 as a biomarker for metastasis, recurrence and of poor prognosis in hepatocellular carcinoma. CANCER LETT. 2011; 310: $35-45$.

17. Donnenberg VS, Donnenberg AD. Stem cell state and the epithelial-to-mesenchymal transition: Implications for cancer therapy. J CLIN PHARMACOL. 2015; 55: 603-619.

18. Bonnomet A, Brysse A, Tachsidis A, et al. Epithelial-to-mesenchymal transitions and circulating tumor cells. J Mammary Gland Biol Neoplasia. 2010; 15: 261-273.

19. Lee JM, Dedhar S, Kalluri R, Thompson EW. The epithelial-mesenchymal transition: new insights in signaling, development, and disease. J CELL BIOL. 2006; 172: 973-981.

20. Hartwell KA, Muir B, Reinhardt F, Carpenter AE, Sgroi DC, Weinberg RA. The Spemann organizer gene, Goosecoid, promotes tumor metastasis. Proc Natl Acad Sci U S A. 2006; 103: 18969-18974.

21. Batlle E, Sancho E, Franci C, et al. The transcription factor snail is a repressor of E-cadherin gene expression in epithelial tumour cells. NAT CELL BIOL. 2000; 2: 84-89.

22. Hajra KM, Chen DY, Fearon ER. The SLUG zinc-finger protein represses E-cadherin in breast cancer. CANCER RES. 2002; 62: 1613-1618.

23. Yang J, Mani SA, Donaher JL, et al. Twist, a master regulator of morphogenesis, plays an essential role in tumor metastasis. CELL. 2004; 117: 927-939.

24. Bloushtain-Qimron N, Yao J, Snyder EL, et al. Cell type-specific DNA methylation patterns in the human breast. Proc Natl Acad Sci U S A. 2008; 105: 14076-14081.

25. Ray PS, Wang J, Qu Y, et al. FOXC1 is a potential prognostic biomarker with functional significance in basal-like breast cancer. CANCER RES. 2010; 70: 3870-3876.

26. Mani SA, Yang J, Brooks M, et al. Mesenchyme Forkhead 1 (FOXC2) plays a key role in metastasis and is associated with aggressive basal-like breast cancers. Proc Natl Acad Sci U S A. 2007; 104: 10069-10074.

27. Eger A, Aigner K, Sonderegger S, et al. DeltaEF1 is a transcriptional repressor of E-cadherin and regulates epithelial plasticity in breast cancer cells. ONCOGENE $2005 \cdot 24 \cdot 2375-2385$.
28. Comijn J, Berx G, Vermassen $\mathrm{P}$, et al. The two-handed $\mathrm{E}$ box binding zinc finger protein SIP1 downregulates E-cadherin and induces invasion. MOL CELL. 2001; 7: 1267-1278.

29. Rafael D, Doktorovova S, Florindo HF, et al. EMT blockage strategies: Targeting Akt dependent mechanisms for breast cancer metastatic behaviour modulation. CURR GENE THER. 2015; 15: 300-312. 